\title{
A Study on Academic Adaptation of International Students in China
}

\author{
Mudassir Hussain $^{1} \&$ Hong Shen ${ }^{1}$ \\ ${ }^{1}$ School of Education, Huazhong University of Science and Technology, Wuhan 430074, P.R. China \\ Correspondence: Hong Shen, School of Education, Huazhong University of Science and Technology, Wuhan \\ 430074, P.R. China. Tel: 86-18672950763. E-mail: hongshen@ hust.edu.cn
}

Received: September 1, 2019

Accepted: September 30, 2019 Online Published: October 5, 2019

doi:10.5539/hes.v9n4p80

URL: https://doi.org/10.5539/hes.v9n4p80

\begin{abstract}
This qualitative study investigated academic challenges, supports and the role of readiness in academic adaptation of international students. 20 international students were recruited for data collection employing semi-structured interviews. The results showed that three types including academic challenges, socio-cultural challenges and language incompetency were affecting the academic adaptation process. In addition, three types of supports including university support, peer support and psychological motivation which helped international students cope with the challenges while readiness played a significant role in balancing challenges and supports. Pre-departure preparedness and on-campus orientation instilled readiness among international students. The study suggested that sending countries should make effective mechanism to prepare the students before their departure. It can include host country's language, its education system, degree requirement, culture, climate and food etc. The study proposed theoretical model of academic adaptation of international students for future quantitative research.
\end{abstract}

Keywords: academic adaptation, international students, readiness, challenges, support

\section{Introduction}

The term "International student" is referred to any students who go abroad in pursuit of learning to a foreign country. All the countries' higher education policy makers are devising new ways of harnessing the secrets of changing conditions which accelerate students' mobility and result in enhancing internationalization of Higher education. The number of students at Chinese universities is increasing every year due to quality of university education, social development and introduction of various types of scholarships i.e. China government scholarships, university scholarships and MOFCOM scholarship. According to the (Project Atlas Infographics, 2018) China holds the 3rd position among the countries, hosting international students with a number of 489,200 international students, United Kingdom holds 2nd position with 506,480 whereas US has the top position hosting 1,094,792 international students. The major population of international students in China is composed of Asian, African, European as well as American students. Chinese Universities are experiencing more complex and a diverse student population. China plays a leading role in Asia hosting international students. Cross-borders collaboration have strengthened higher education in Asia (ADB, 2012) and these Higher Education Institutions (HEIs) are focusing on different fields; cross culture exchange, faculty training and development, policy making, human resource management and international students' mobility (Skamato, \& Chapman, 2010). The recent Chinese Belt and Road (B\&R) Initiative boosted up students' mobility besides all the countries along with the Belt and Road (B\&R) Project. Thus, China attracts more international students by providing them with quality education in Chinese universities and providing a huge number of students with fully funded scholarships.

Literature on international students has generally well-known three domains of adaptation: psychological, socio-cultural and academic adaptation. This will begin by presenting notable challenges confronting international students found in the literature of previously conducted research studies and move on to problems related to their academic adaptation. This study will add some more discussion based on other related issues academic challenges and adaptation, socio-cultural adaptation, student readiness and coping strategies. Living and learning in an unfamiliar socio-cultural and academic environment, international students are challenged with a number of problems including depression, stress, anxiety, insomnia, culture shock, loneliness and homesickness, food and lodgings, language incapability, understanding lectures, learning social norms and interacting with people from different cultural backgrounds etc. Stressors among international students not only have an impact on their physical and psychological well-beings but also obstruct the capability to participate 
fully in cultural assimilation and academic outcomes. The study aimed to explore challenges and supports including their readiness to confront these stressors while adapting to the Chinese socio-cultural and educational environment.

The study aimed to explore how International students in China cope in balancing challenges and support by showing their readiness and how they describe their coping strategies while adapting to Chinese Universities and new academic environment. The study also aimed to suggest more practicable way of effective academic adaptation to international students for their productive academic outcomes. Furthermore, the study aims to give recommendations and suggesting for improving the academic and service quality at Universities.

\section{Literature Review}

Previous studies on international students have revealed that international students who are far away from their families and friends often experience challenges of various types including cultural, social, psychological and psychological. In addition, international students who migrate for the pursuit of their academic achievements, experience academic challenges. Numerous researchers found that international students face occasionally an unwanted interaction which affects their adaptation to the new environment (Rose-Redwood, 2010). Trice (2004) quantitative study targeting 497 and investigating the social interaction of international students with the host students in America reported the international students feel lonely and find themselves in isolation. She found out that this isolation is because these international students lack effective social network and interaction with local students. she concluded that if international students engage themselves with local students, they can better understand the culture and academic set up and can effectively adapt to new environment. Trice (2004) suggested that hosting universities should help international students to interact occasionally with the local students and the students' affair personnel should engage internationals students in co-curricular activities. She asserted that the universities should manage an effective orientation program for international students so that they can understand the culture and habits of local students which will enhance the coping strategies of international students while facing social challenges.

International students face challenges to adapt to new academic environment as well as they have to master new skills. Studies showed that international students face difficulties in understanding the culture and language of the host country. Unfamiliarity with the new academic system often generates difficulties for international students (Lin \& Yi, 1997). New educational system, with a completely new design, new assessment methods and having different demands lead international students to variety of difficulties. Fulfilling the demands of new academic systems, international students face numerous challenges including assessment, course selection, understanding lecture, communication with teachers and home assignments etc. A study conducted by (Cigularova, 2005) has concluded that international students experience many challenges while adapting to the new environment. International students face different challenges i.e. academic difficulties, cultural issues and difficulties in daily activities (Selvadurai, 1992).

International students need to live in the host culture and society. Their lives and activities should be confined to campus environment, but due to different culture and language incompetency, international students often find it difficult to readily adjust to the host society (Zimmerman, 1995). Zhang (2004) conducted a study on 102 Chinese Students who were studying in the universities of USA, found out that the different education system, different academic demands and interaction with the local students are the major challenges of international students.

Culture differences create uneasiness among international students and they hinder the process of acculturation. Cultural adaptation is crucial for international students because it decreases psychological pressure among international students. Many researchers found that international students face difficulties in adjustment process while adopting into the new culture (Ward \& Kennedy, 2001). Prior literature on cross-cultural adaptation of international students confirms three significant domains including academic adaptation, socio-cultural adaptation and psychological adaptation. All the three combined make a multi-dimensional process (Brisset, et al., 2010; Zhang, J., \& Goodson, P., 2011). Academic adaptation of international students referred to how these students cope with the demands of academic environment and enhances their motivation to get academic achievement (Rienties, Beausaert, Grohnert, Niemantsverdriet, \& Kommers, 2012). Academic adaptation in a cross-cultural environment is a different term than academic adaptation within one's own country and familiar educational systems. International students' academic adaptation is more of a complex process because of its multi-dimensional obligations and difficulties of understanding new system and culture. International students who adapt well into academic environment tend to have better academic outcomes (Rienties, 2012). International students live in unfamiliar culture without family and friends' supports often tend to isolation. Lacking social 
networks, cultural associations and tagged as "Foreigners" develop feelings of insecurity and depression among international students. Besides day to day affairs, dealing with academic demands, international students face positive and negative experiences which significantly affect the process of academic adaptation (Ramsay., Barker, \& Jones, 1999). In his study, Ward and Searle (1991) found that personality factors and social support impact psychological adaptation of international students. Improper psychological adaptation leads students into depression, mood disturbances and mental stress. Close interaction with the local students develops a social network which promotes both socio-cultural and psychological adaptations (Zhang, \& Goodson, 2011). Ward and Searle (1991) defined socio-cultural adaptation as the ability to adjust in and negotiate with the host culture. There are numerous significant factors that enhance the socio-cultural adjustment of international students as Church (1982) based on his study findings illustrated that acquaintances with local students increase satisfaction and tend to decrease the feelings of homesickness. Researchers examined the factors that facilitate sociocultural adjustment of international students.

Sanford (1968) posited that challenges and supports are crucial for students learning and development in universities. According to Sanford, there are three major conditions responsible for students' development: readiness, challenges, and support. Sanford postulated that process of learning and development should be beads on challenges and supports. Challenges and supports are crucial for effective development. There should be a balance between challenges and support. Unequal challenges and supports usually lead to unsatisfactory adaptation. If there are not enough academic challenges, the students may feel easy and satisfied, and tend to halt studies. If the challenges are too many for the student without proper support mechanism, the students may go into depression and psychological stress. (Dalton, 2008) Study also came to the conclusion that challenges play a vital role in students' academic life to enhance their reflection and academic motivation but on the same time supports are important to help students cope with the demands of the challenges. Challenges provide opportunity to students learn to face difficulties and promote their problem solving and decision-making skills as well as they polish the potentialities among students to cope with different conditions by showing resilience. Universities attempt to highlight challenges to inculcate among students' intellectual characteristics. They anticipate students to develop independence, flexibility in their behavior and coping strategies (Dalton, 2008).

Students' readiness to enroll and study in universities is referred to preparation to achieve their academic goals. This preparation motivates the students and helps them cope with the challenge of academic demands (Conley, 2007). Previous studies found that there are many other factors that contribute to student's readiness for university education including time management, motivational factors, students' background, and self-concept (Byrd, \& MacDonald, 2005). Student preparation should be comprehensive that should cover all the important aspects of understanding the admission process, financial issues and determination that would guarantee their success (Conley, 2007). Conley states that students should be fully aware about the country's climate and study program. Their contextual knowledge which should include the campus environment and they should know how to cope the changes during the period of transition.

Transition brings new experiences to international students because they have to compromise their own social norms, social values and mental outlook. Transition referred to any event or non-event which brings about change in routine, relationships and roles (Schlossberg, Waters, \& Goodman, 1995). He further categorized transition into its three types i.e. anticipated transition, unanticipated transition and non-event transitions. To get enroll into a university after completing high school certificate is simply an example of anticipated transition while these students who wish to enroll in university but cannot due to financial restrains or choice of major is unanticipated transition. Similarly, international students focus on the choice of higher educations' institutions for their study abroad. There are many factors that frame their choice of selections like scholarship, international ranking, indigenous ranking, faculty, number of international students and location. If students are successful in getting admission into universities of their choice, it enhances their level of satisfaction because they will undergo an anticipated transition. Enrollment into a university without their choice creates demotivation and mental tardiness which ultimately lead to unsatisfactory academic outcomes.

This study aimed to explore how International students in China cope in balancing challenges and support by showing their readiness and how they describe their coping strategies while adapting to Chinese Universities and new academic environment. The study also aimed to suggest more practicable way of effective academic adaptation to international students for their productive academic outcomes. Furthermore, the study aimed to give recommendations and suggestions for improving the academic and service quality at Universities. The rationale for this study is that there are increasing numbers of international students in China, and international students are a diversified population. To improve the academic achievement, these students need to adapt academically to the new educational environment. This study focused on in-depth exploration of their challenges 
and supports, they experience during academic journey in China.

\subsection{Research Questions}

1) What are the academic challenges that affect academic adaptation of international students in Chinese Universities?

2) What are the supporting services that help international students to adapt academically in Chinese Universities?

3) What is the role of Readiness in balancing challenges and supports while adapting to Chinese academic environment?

4) What are the factors that promote readiness among international students?

\section{Method}

Literature review provides the researcher with a direction and guideline for research design. Semi-structured interviews were taken from the respondents. Interviews were focused mainly on the Research Questions. Research method is very important to be appropriate to the research problem with selected paradigms and methodologies shaping the choices of methods (Silverman, 2010). Data collection in qualitative research through interviews provides rich and in-depth details. Interviews allow the respondents to express freely and to share more reliable and authentic experiences with the researcher. Through interviews a diverse data can be acquired which can explore new trends in the field of interest. Semi-structured interviews allow the interviewees to express themselves freely. The semi-structure interview is a tool of data collection that gives the interviewer a scholastic flexibility by asking prompts question where necessary (Creswell, 2009).

The same semi-structured interviews were conducted in two different universities located in Wuhan, Hubei, the central province of China. We recruited 20 international graduate students ( 7 females, 13 males) studying in two universities in Wuhan, Central China Province Hubei and were investigated on semi-structure interview (Table 1). All students were graduate and sponsored by the Chinese Government. Convenient sampling method is used when the goal of research is to understand and describe a particular group in depth (Cohen \& Crabtree, 2006). Each participant was interviewed at a time and each interview lasted for 30-35 minutes. The interviewees were assured that the data will be purely used for research purposes and their confidentiality will be guaranteed. The interview had also been recorded for its validity. For data coding, initially the interview transcripts were thoroughly and carefully read several times to get a holistic view of the participants. The codes were made manually and color-coding technique was used (Creswell, 2009) to easily capture the insight from highlighted coded themes. The most recurring codes were labeled as themes. Thematic analysis was made on the explored themes on the semi-structured interview response transcript. The themes were categorized and merged into superordinate themes for further producing a report. Then the originated themes were allotted acronyms for data analysis.

Table 1. Demographic information of participants

\begin{tabular}{llllllll}
\hline Code & Gender & Age & Degree & Year & Fin/status & Discipline & Nationality \\
\hline S.1 & $\mathrm{M}$ & 30 & PhD & $2^{\text {nd }}$ Year & CSC & Physics & Pakistan \\
S.2 & M & 25 & Masters & $2^{\text {nd }}$ Year & CSC & Management & Iraq \\
S.3 & $\mathrm{F}$ & 27 & PhD & $2^{\text {nd }}$ Year & CSC & Chemistry & Pakistan \\
S.4 & M & 21 & Undergraduate & $2^{\text {nd }}$ Year & CSC & Electrical & Sri Lanka \\
S.5 & $\mathrm{M}$ & 25 & Masters & $1^{\text {st }}$ Year & CSC & Economics & Bangladesh \\
S.6 & $\mathrm{F}$ & 23 & Masters & $1^{\text {st }}$ Year & CSC & Mechanical & Poland \\
S.7 & $\mathrm{F}$ & 26 & $\mathrm{PhD}$ & $1^{\text {st }}$ Year & CSC & CS. & Uzbekistan \\
S.8 & $\mathrm{M}$ & 25 & Masters & $1^{\text {st }}$ Year & CSC & Food Sciences & Russia \\
S.9 & $\mathrm{M}$ & 27 & $\mathrm{PhD}$ & $1^{\text {st }}$ Year & CSC & Optics & Pakistan \\
S.10 & $\mathrm{F}$ & 31 & $\mathrm{PhD}$ & $3^{\text {rd }}$ Year & CSC & Management & Turkey \\
S.11 & $\mathrm{M}$ & 27 & $\mathrm{PhD}$ & $2^{\text {nd }}$ Year & CSC & Education & Ethiopia \\
S.12 & $\mathrm{F}$ & 26 & $\mathrm{PhD}$ & $2^{\text {nd }}$ Year & CSC & Botany & Togo \\
S.13 & $\mathrm{M}$ & 23 & $\mathrm{Masters}$ & $1^{\text {st }}$ Year & CSC & Engineering & Iran \\
S.14 & $\mathrm{M}$ & 31 & $\mathrm{PhD}$ & $3^{\text {rd }}$ Year & CSC & Economics & Tanzania \\
S.15 & $\mathrm{F}$ & 24 & $\mathrm{Masters}$ & $2^{\text {nd }}$ Year & CSC & Chemistry & Ghana \\
S.16 & $\mathrm{M}$ & 28 & $\mathrm{PhD}$ & $3^{\text {rd }}$ Year & CSC & Finance & South Africa \\
S.17 & $\mathrm{M}$ & 30 & $\mathrm{PhD}$ & $3^{\text {rd }}$ Year & CSC & Education & Indonesia \\
S.18 & $\mathrm{F}$ & 32 & $\mathrm{PhD}$ & $3^{\text {rd }}$ Year & CSC & Economics & Mexico \\
S.19 & $\mathrm{M}$ & 24 & $\mathrm{Masters}$ & $2^{\text {nd }}$ Year & CSC & Management & Brazil \\
S.20 & $\mathrm{M}$ & 29 & $\mathrm{PhD}$ & $2^{\text {nd }}$ Year & CSC & Economics & Thailand \\
\hline
\end{tabular}

Note: $\mathrm{S}=$ Student; $\mathrm{M}=$ male; $\mathrm{F}=$ female; $\mathrm{CSC}=$ China Scholarship Council 


\section{Results}

\subsection{Challenges}

The results of the study up to some extent are in concordance with the findings of other researchers (Poyrazli \& Kavanaugh, 2006; Ramburuth, 2001). Previous studies illustrated that international students faced various challenges in different universities especially during their transition periods. This study indicated that international students in China experienced challenges in three major areas, which were: Academic challenges, socio-cultural challenges and language challenges. The findings of this study show that there are many factors that contribute to the challenges of international students in China including new educational system, unfamiliar academic environment; academic demands research techniques and understanding research materials. As some of the respondents from African countries stated that they are experiencing the grading system for the first time and didn't understand it. Furthermore, responded that class material and research techniques are a unique pressure on her because she didn't have any previous experience in research. Some countries' education systems allow graduate students to choose courses in lieu of research thesis that leads to research impotency at $\mathrm{PhD}$ level. Therefore, such students face more academic adjustment challenges as compared to those having know-how of research method and practice of primary level. As respondent S-2 exclaimed also admitted that he struggled hard to adjust to this new academic environment.

"Education system is different as compared to what was known to me. Our research background wasn't very sound and the notable challenge was English which is our second language. However, a few classes and classmates, interaction with supervisor and researchers, group meetings with friends, now I feel I can do it. All this came true after a lot of struggle"- $S 2$.

These results show that international students should be given effective orientation and courses which tend to help them in understanding the new educational system. This develops a sense of understanding among international students and they do not need discomfort. Secondly, the coursework needs to be in accordance with the research and major's needs. International students belong to different educational backgrounds so similarly they require different treatment. This result concludes that international students are with different personalities, family background, educational backgrounds and individual differences so they cannot be assessed on a homogenous criterion unless they are all given an effective and productive training before stepping into the research zone.

Table 2. Qualitative Finding 1(challenges)

\begin{tabular}{lll}
\hline Super-ordinate Theme & \multicolumn{1}{c}{ Theme } & Themes' Description \\
& & Difficulty understanding my major. \\
& Difficulty understanding research material. \\
& & Difficulty discussing research material with professor. \\
& & Difficulty understanding degree requirement. \\
& Difficulty adapting into new academic environment. \\
& Difficulty making friends. \\
& Difficulty communicating with staff members. \\
& Socio-cultural challenges & Difficulty attending student's organization. \\
& Difficulty understanding campus culture. \\
& Difficulty participating in extra-curricular activities. \\
& Difficulty communicating in Chinese. \\
& Difficulty communicating in English with classmates. \\
& Difficulty accessing Chinese search webs. \\
& Difficulty understanding university instructions in Chinese. \\
& Difficulty in academic writing in English. \\
\hline &
\end{tabular}

This study finding is similar to the findings of previous researches conducted by (Poyrazli; Arbona; Bullington \& Pisecco, 2001) which illustrate that for academic achievements, language competency is crucial. It is important for international students to mix within the local classmates to acquire cultural knowledge and to learn Chinese language, which will result in effective socio-cultural adaptation as well as academic adaptation. Similarly, international students should interact frequently with other international students to share their cultural experiences and improve their English skills by practicing. One unique finding of the study is that some international students reported that they face challenges in understanding their majors. Higher education in China is flexible and the supervisors are experiencing academic freedom, the students who had a master's degree qualification in engineering can seek $\mathrm{PhD}$ admission in any other field of study like management, economics etc. The findings illustrate that this kind of practice weakens the students' content knowledge and negatively affects 
academic outcomes. For instance, an interviewee narrated that he had to struggle to learn even the definitions of his newly opted majors.

"My master's degree is in Mathematics but here I opted economics for my PhD research, I found it extremely irrelevant and hard to but I struggled and now I am hopeful to be succeeded"-SI4.

There was a common challenge found as the result of the study that mostly international students are sponsored by Chinese government for the three-year period, extendable for fourth year based on supervisors' recommendation. Three years to fulfill the laid criterion is quite tough and require students to have a tight study schedule which causes severe study pressure. The students do not feel comfortable in their daily activities due to an apprehension of degree requirements within the given time frame. As a respondent stated,

"My first year was spent in course work and adaptation to social ad physical environment, now I realize that time is short and I need to work day and night lest I might not get fail to win my degree within stipulated time" $-S 10$.

The study findings show that there are many challenges international students face in China as international students face in any other country. This is a common phenomenon to experience difficulties adjusting to the new environment and adapting to an unfamiliar academic system. The respondents expressed their concerns on many issues, like relationships with supervisor, understanding course material, research technique, and difficulty making friends, difficulty understanding campus culture and participating in extra-curricular activities. Similarly, international students in China face difficulties in language. Chinese' language acquisition is difficult and generally any language to master would take time. Thus, students challenge of language like difficulty communicating with staff, difficulty communicating outside classroom etc. The study recommends that, maximum interaction with the host mates would help international students learn language, know cultural differences, and it would avoid feeling of insecurity and will decrease the feelings of homesickness.

\subsection{Support}

The study findings show that there are many challenges which are impacting the social and academic dimensions of international students in China. Some of them are of serious, depending on the individual's personality type which can deteriorate students' health if they don't use effective coping strategies to face the challenges. International students utilize various support services, which are provided by many agencies. Physical, financial and mental support helps international students cope with the challenges and be optimistic regarding academic outcomes. Chinese government and universities have a system of orientation and supports mechanism for international students which include academic support, financial, support, health support etc. The respondents of this duty are all financially sponsored students. The students pay attention on their studies to fulfill the academic demands and to fulfill the degree criterion within the scholarship timeframe. Thus, they express their satisfaction financially.

"I focus on my studies and I'm satisfied because I don't care for my financial issues because I am a scholarship student. It helps me finish my study in time and successfully"- S12.

A significant result of the student was that international students at this stage of age and educational levels find it hard to assimilate in this new culture. International students migrate for their academic purpose with a sound vision and aim of going back home and serve their nations. Their cultural values and identities do not allow them to acculturate for it they do this they will fell a sense of guilt. Therefore, the study findings show that international students in China are experiencing difficulties in making changing their minds regarding daily routine activities and other cultural programs. A participant expressed herself as;

"It's a bit difficult to adjust to new culture and society but I had the knowledge of Chinese culture, food and city climate. Above all my friends who were already studying here, guided me so effectively that I adjusted soon and I'm satisfied with my academic outcomes"- S7. 
Table 3. Qualitative Finding 2(supports)

\begin{tabular}{lll}
\hline Super-ordinate Theme & Theme & Themes' Description \\
\hline & & Academic support services, course registration etc. \\
& Supervisor research guidance, article publishing etc. \\
& Fniversity support & Accommodation; housing, transportation, entertainment. \\
& Health insurance; playgrounds, gyms etc. \\
& Social gathering and cultural belongingness \\
& Research assistance \\
& Support in daily routine activities. \\
& Emergency support and assistance. \\
& & Moral support, inspiration. \\
& & Study abroad experience, cross cultural learning \\
& Scholarship. \\
& Quality education, research-based degree. \\
& Job opportunities, future optimism. \\
& PhD. as honor, self-esteem. \\
\hline &
\end{tabular}

Findings showed that international students sought for support from their peer. Peer support plays a significant role as a coping strategy against challenges. They sought supports from university staff including ISO (International Student Office) and their respective supervisors. Results indicated that the source of satisfaction and the key support is the role of country-mates in China. These students, who are far from their families and friends, live in China in association, having commonness of culture and challenges. They help one another and they use WeChat and QQ to connect interact with one another. This may be due the fact that peer support helps to reduce stress experienced by the participants. Students need motivation and moral support which they get from their country-mates. A participant stated as;

"In my opinion there is more freedom in graduation studies but blended with excessive responsibilities. I always seek help and motivation from my country mates, class mates and supervisor. This is what boost my academic and social life"- S10

Students often feel isolated because of their distance from families. They need support of the family and friends especially in a foreign country. Results showed that students express the feelings of loneliness which is due to their rare engagements in social activities. A student who is involved in cross-cultural groups and country-mates' gatherings is more satisfied. It is possible that a student who is sufficiently incorporated in the academic system but not in the social system can still decide to withdraw. This engagement gives satisfaction to international students and it helps decrease the sense of isolation.

"I feel happy to be the part of my country mates' social networks; our gathering helps me avoid home sickness. We discuss occasionally research related material to help support one anther" - S1.

By doing so, the network among international students grows stronger and this helps to reduce other psychological issues such as loneliness and homesickness. It reduces fear amongst international students. They boldly take parts in social and academic activities. Upon any need or emergency, country mates and peer can be the first source of support. They help reduce stress, depression and accelerate adaptation on-campus and out of campus.

\subsection{Readiness}

Students undergo a transition phase they enter the institutional environment. According to the readiness and retention model, the students who are ready for university education are more likely to have a smoother transition phase, be academically successful, and persist (Conley, 2007). As responded by a PhD student that he was fully aware before coming to China about campus life and academic requirements;

"International students office provided me with sufficient literature that enlightened me before my arrival, which made me cope the challenges and adapted well enough!"- 59 .

The results highlight the importance of pre-departure preparedness for an effective acculturation and academic adaptation. There are various agencies that promote pre-departure preparedness, including international students' office (ISO), family \& friends, school syllabus, scholarship and motivation for study abroad. A very significant agency that influenced students to readily accept China as study destination is their home country's school 
syllabus. A student from Pakistan quoted,

"When I was a child in grade 7, I leant about China's geography, culture and traditions. It is the part of our social studies course book." SI.

The other important findings of the study are motivation for study abroad experiences also triggers the willingness of international students to face challenges confidently and make the best utilization of the available supports/facilities. In 2013, China launched Belt \& Road initiative for the world's shared future and was welcomes by numerous nations of the world. Chinese governments-initiated scholarships at higher education level to the talented students belonging to the countries along with Belt \& Road. This financial assistance stimulates students' interest to flock to China, get their degree and go back home countries and play their role in nation building. As $S 17$ stated,

"Thanks to China for quality education and fully sponsored too. I couldn't even imagine to study here without scholarship- "S17.

The findings are in concordance with the study of (Bean, 2005; Tinto, 1993) that family and peer supports and personal locus of control are valuable resources for coping and seeking information. Interviews depict the same as;

"I know some of my friends were studying in China and I was in contact, it was a really a source of motivation and comfort for me." S5.

Lack of preparedness and awareness lead students to withdraw from their courses or show tardiness during class and sometimes slip away from class. The exit interviews show that mostly it happened because unanticipated choice of subject/majors or program which generates lack of motivation that ultimately results in low grades or poor academic outcomes. Persons who lack motivation, regardless of great goals, will not be able to commit themselves to attain initial goals (Tinto, 1993).

Table 4. Qualitative Finding 3 (Readiness)

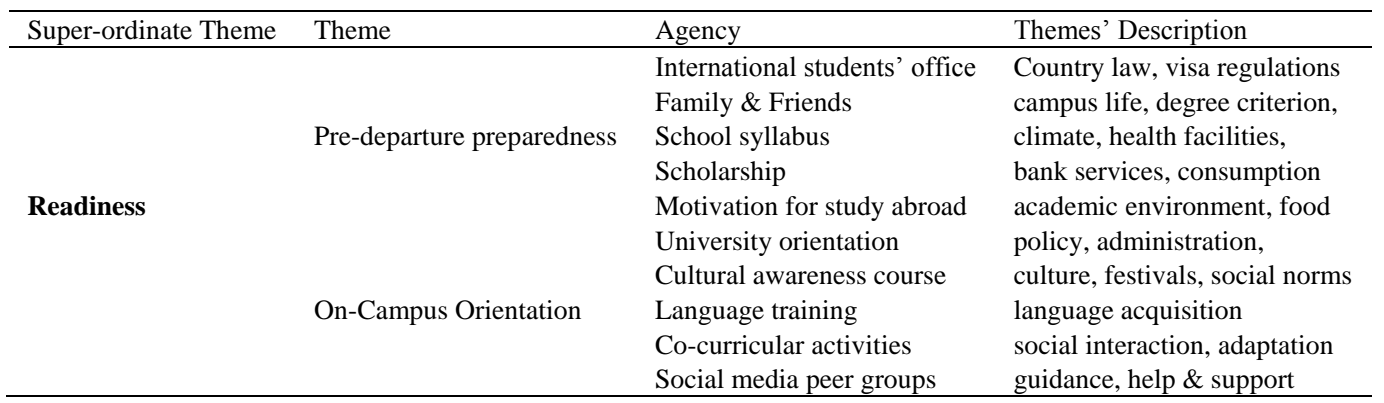

Campus life is crucial to academic success for international students. It is a comprehensive modeled infrastructure, providing opportunities, availing resources and shaping students' personalities. International students who are a minority population in every university need vigorously to involve in campus activities and make the possible use of available resources. In this regard, ISOs are playing a vital role in socializing new comers, since their arrival till their departure. The study results show that ISOs' effective orientation helps international students know about academic and social life in China, including challenges and supports and how to cope with them. A respondent stated in these words,

"I was received at airport; volunteers assigned by ISO helped me register at school and at hostel. The orientation (2) days class, really opened my eyes about laws, library use, visa policy, foods, health and so on ... "-S15.

Moreover, the study finds that readiness plays a significant role in balancing challenges and support of international students. International students who are in a new culture and academic environment are usually confronted with the variety of unfamiliar and unfavorable circumstances. These physical and psychological challenges can effectively be overcome if international students have the readiness and motivation for their academic achievement. Readiness helps international students show persistence and make systematic use of supports given by the university or host country. Generally, these students get ready to travel abroad and ready to study enthusiastically by two kinds of preparedness including pre-departure preparedness and on-campus orientation programs. The agencies involved in the former are international students' office, family \& friends, school syllabus, scholarship and motivation for study abroad whereas the later includes University orientation 
program. Cultural awareness course, Language training, Co-curricular activities and Social media peer groups.

\section{Discussions and Theoretical Outcome of the Study}

This study was focused on international students growing number in China from different part of the world and their academic adaptation. The primary aim of these international students is to study in China and to ensure academic achievements. Literature review shows that international students very often face difficulties of various dimensions including physical, academic, socio-cultural and psychological challenges. Students who due to lack of support or personality introversion do not assimilate in the host culture are marginalized and are at risk of depression, insomnia, and stress while those who readily adapt to host culture, academic environment and balance effectively the challenges and supports, become the happy part of new society and undergo positive changes. Thus, effective adaptation ensures academic achievement within the given time frame for international students. A remarkable number of international students are sponsored by Chinese government for a specific period of 3 or 4 years. This timeframe also is a challenge for international students, having a very positive impact as well. Students keeping in their minds the timeframe which make them realize to lead an organized academic and campus life and to make maximum use of the library and other resources to get through the assessments. Results showed that international students in China are confronted with academic challenges including difficulty in understanding educational system, research material and techniques and they find difficulty in English academic writing as well. These challenges have also been recorded in previous literature. As international students and researcher, the best possible solution to counter these challenges is to be associated with classmate either international friends or locals.

As all participants in this study were sponsored, these students were obligated to excel in their academic performance and return to their countries within the time frame given. In order to succeed academically, these students need to schedule their daily lives and focus on academic as well as their social activities. International students have to be ready to change their daily routine in order to accommodate to the new rules and regulations in China. Study findings illustrate that a significant supporting agency is peer and classmates. Thus, international students should make the fullest use of friends in help-seeking and should have a good interaction with local classmates and students to have a balanced life in new society. The more integrated and socially active these students are, the more engaged and happier these students will be. Social gatherings help develop a sense of belongingness and avoid the feelings of homesickness, fear and culture shock. University support especially the academic support from supervisor plays a prominent role in effective adaptation and academic outcomes. Supervisors, who push international students to work together with Chinese students as group or team to conduct research projects together, are undoubtedly supporting students socially and academically. Such a collaborative team work on one hand provides opportunity to international students to acquaint with the local students and on the other hand they share academic knowledge and seek support where it is needed.

The study contributed to scientific knowledge by showing the readiness characteristics of international students that are related balancing challenges and supports in China. Readiness is an important contribution of this study which generates an academic adaptation model based on Sanford Theory of challenge and support for international students. According to Sanford (1968), Readiness+ Challenges + Support=outcomes, are modeled and can be used for international students' academic adaptation where both Challenges and supports as independent variables maybe mediated or moderated by readiness and lead to the dependent variable outcomes/ academic adaptation. 


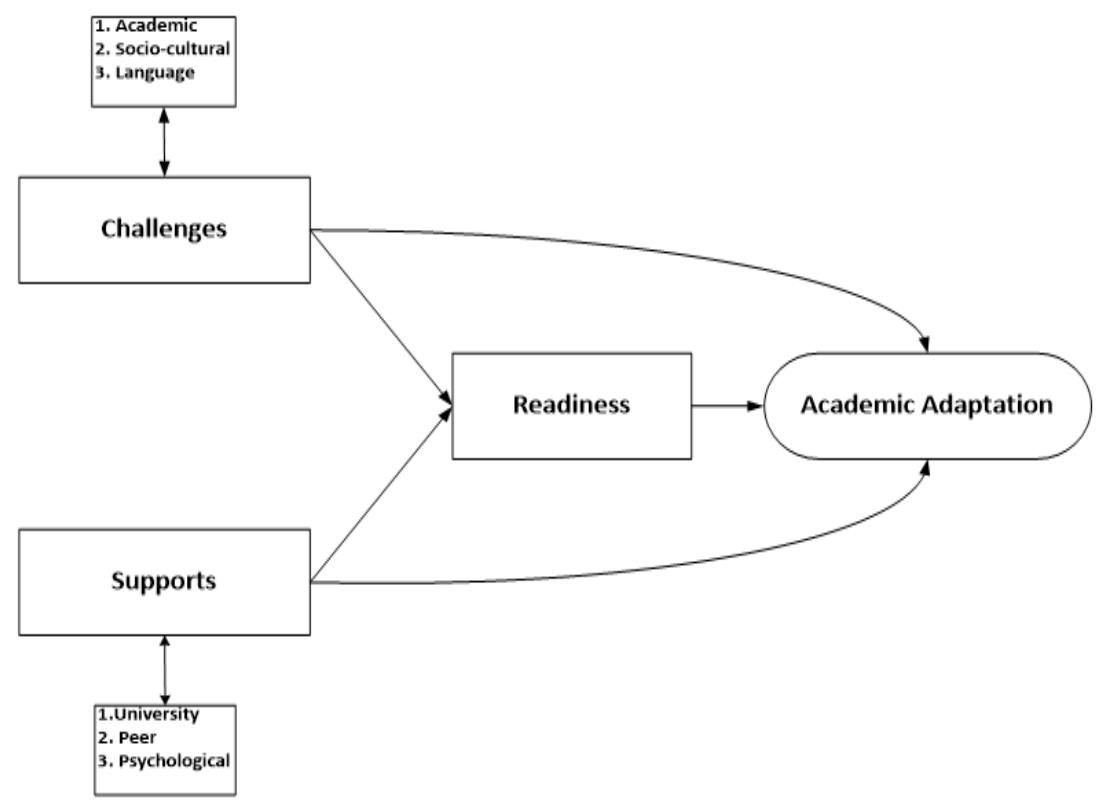

Figure 1. Theoretical outcome of the study

Institutions do not always understand the entering student, nor do they know what are the group-differences are. A scientific approach to enhance the readiness of students can ensure a productive academic life on campus. A further contribution to scientific knowledge is the development of a concise theoretical model which covers comprehensive cluster of related variables that affect international students' academic adaptation and outcomes. The model is based on a theoretical foundation that can be used by future researchers to understand the adaptation and balance between challenge and support. The Readiness as variable is the significant contribution of the study which mediates between challenges and supports and the study's findings show that the more readiness students have the more productive and comfortable they are.

\section{Conclusions}

The study findings illustrate that international students in China are the most diverse population and belong to different academic, social and political backgrounds. International students constitute a complex society by sharing their experiencing, living together and influence one another. Different psycho-social outlooks and background are challenges that generate obstacles in international students' mutual understandings and socialization. The same international students who are different among themselves are labeled as a single group titled foreign students. While migrating to China, the primary aim of all these students is to get quality education and receive cross-cultural wisdom. China is a developed country and accommodates a large population of international students in colleges and universities. Thus, China Ministry of Higher Education provides financial assistance to international students and universities ensure the required facilities like quality education, accommodation, library services, health and recreation etc. Hence, previous literature on International students confirms that these students face challenges despite they are provided with generous support like financial, social, psychological and academic.

This study results explored the challenges of international students in China. There are three basic categories of challenges i.e. academic challenges, socio-cultural challenges and language challenges which are further linked to other sub-categories. The study found that there are three main categories of support that they get while they are studying in Chinese Universities i.e. university, peer and psychological/motivation. In addition, the significant finding of the study is Readiness. Readiness helps international students cope the challenges, keep them motivated, engage them in social gatherings with country mates, other international students and local class mates which decrease psychological stress of homesickness, culture shock and enhance academic achievement. The study results showed that pre-departure preparedness and on campus orientation excel readiness among international students. The students responded positively on readiness, showing an effective Chinese government's and universities' international students counseling strategies. Pre-departure preparedness is the 
output of students' activities at their host countries before arrival. They include international students' office, family \& friends, school syllabus, scholarship, motivation for study abroad. While on-campus orientation provides awareness to international students who are newly arrived about campus life, university resources, academic obligations, city climate, and country laws etc. It includes university orientation, cultural awareness course, language training, co-curricular activities and Social media peer groups.

Therefore, based on the findings of the study, we concluded that a diverse international students' population do face challenges while they are in Chinese universities in different levels. The main focus of the study was on academic adaptation and the factors that contribute to this adaptation. We suggest that sending countries ministries of education or education system should make effective mechanism to prepare the students before sending to China. It can include Chinese language, awareness about Chinese education system and degree requirement, culture, climate and food etc. This pre-departure preparedness will decrease homesickness by familiarizing with the new environment in advance which resultantly enhances readiness. The host country's universities should engage international students in co-curricular activities which make international students adapt into the new academic and social environment. Based on the result of the study, the supervisor should schedule the activities of the students which will help them organize their lives and will fulfill their degree requirements within due timeframe. English as second language for both supervisors and students develops a gap of communication and cause misunderstandings. This can be solved by using oral and written both as communication technique. Therefore, it is hoped that the present study will help future international students improve their preparation before arriving to China. Also, the findings and suggestion can enlighten the universities' professors and ISO staff to know the challenges and further enhance their support and services for better utilization of international students.

Acknowledgement: This work was supported by the National Natural Science Foundation of China (NSFC), grant number [71673097].

\section{Conflict of Interest}

The authors declare no potential conflict of interest.

\section{References}

ADB. (2012). Reagional Cooperation and Cross-border Collaboration in Higher Educationin Asia: ensuring that everyone wins. Retrieved from http://www.adb.org/sites/default/files/publication/2F93/regional-cooperation-higher-education-asia.pdf

Bean, J. (2005). Nine Themes of College Student Retention. In A. Seidman (Ed.), College Student Retention: Formula for Student Success (pp. 215-243). Westport: Praeger Publishers.

Brisset, C., Safdar, S., Lewis, J. R., \& Sabatier, C. (2010). Psychological and sociocultural adaptation on university students in France: The case of Veitnamese international students. International Journal of Intercultural relations, 34(4), 413-426. https://doi.org/10.1016/j.ijintrel.2010.02.009

Byrd, K., \& MacDonald, G. (2005). Defining College Readiness from the Inside Out: First Generation College-student Perspectives. Community College Review, 1(33), 22-37. https://doi.org/10.1177/009155210503300102

Church, A. T. (1982). Sojourner adjustment. Psychological Bulletin, 91(3), 540. https://doi.org/10.1037/0033-2909.91.3.540

Cigularova, D. (2005). Psychosocial Adjustment of international. Colorado State University Journal of Student, 14.

Cohen D., \& Crabtree B. (2006, July). Qualitative Research Guideline Project. Retrieved from www.qualress.org/Home-3804.html

Conley, D. (2007). Redefining College Readiness (Vol. 3). Center for Educational Policy Research: University of Oregon.

Creswell, J. W. (2009). Research Design: Qualitative and Mixed Method approaches, 3rd ed. Sage Publications Inc., Thousand Oaks, CA.

Dalton, J. (2008). Challenging college students to learn campus cultures of comfort, convenience, and complecency. Journal of College and Character, 9(3), 1-15. https://doi.org/10.2202/1940-1639.1112

Lin, J. C. G., \& Yi, J. K. (1997). Asian international students' adjustment: Issues and progrsm suggestions. College Student Journal, 31, 473-479. 
Poyrazli, S., Arbona, C., Bullington, R. \& Pisecco, S. (2001). Adjustment issues of Turkish college students studying in the united States. College Student Journal, 35(1), 52-62.

Poyrazli, S., \& Kavanaugh, P. R. (2006). Marital status, ethnicity, academic achievement, and adjustment strains: the case of graduate international students. College Student Journal, 40(4), 767-780.

Project Atlas Infographics. (2018). Retrieved from https://www.iie.org/en/Research-and-Insights/Project-Atlas/Explore-Data/Current-Infographics

Ramburuth, P. (2001). Language diversity and the first-year experience: implications for academic achievement andlanguage skills acquisition. Journal of the First-Year Experience \& Students in Transition, 13(2), 75-93.

Ramsay, S., Barker, M., \& Jones, E. (1999). Academic adjustment and learning processes: A comparison of international and local students in first year university. Higher Education Research \& Development, 18(1), 129-144. https://doi.org/10.1080/0729436990180110

Rienties, B., Beausaert, S., Grohnert, T., Niemantsverdriet, S., \& Kommers, P. (2012). Understandind academic performance of international students: The role of ethnicities, academic and social interaction. Higher Education, 63(6), 685-700. https://doi.org/10.1007/s10734-011-9468-1

Rose-Redwood, C. (2010). The challenge of fostering cross-cultural intercation: A case study of international graduate students' perceptions of diversity initiative. College Student Journal, 44(2), 389-399.

Sanford, N. (1968). Where colleges fail: A study of student as person. San Francisco, CA: Jossey-Bass.

Schlossberg, N. K., Waters, E. B., \& Goodman, J. (1995). Counseling Adults in Transition: Linking Practice with Theory (2nd ed.). New York: Springer Publishing Company, Inc.

Selvadurai, R. ( 1992). Problems faced by international students. Community Review.

Silverman, D. (2010). Doing Qualitative Research, 3rd ed. London: Sage Publications.

Skamato, R. (ED), \& Chapman, D. W. (2010). Cross-Border Partnership in Higher Education in Asia: Strategies and Issues. New York: Routledge. https://doi.org/10.4324/9780203849262

Tinto, V. (1993). Leaving College: Rethinking the Causes and Cures of Student Attrition. Chicago: The University of Chicago Press. https://doi.org/10.7208/chicago/9780226922461.001.0001

Trice, A. (2004). Mixing it up: International graduate students' interactions with American students. Journal of College Student Development, 45(6), 671-687. https://doi.org/10.1353/csd.2004.0074

Ward, C., \& Kennedy, A. (2001). Coping with cross-cultural transitions. Journal of Cross-cultural Psychology, 32(5), 636-642. https://doi.org/10.1177/0022022101032005007

Ward, C., \& Searle, W. (1991). The impact of value discrepencies and cultural identity on psychological and sociocultural adjustment of sojourners. International Journal of Intercultural Relations, 15(2), 209-224. https://doi.org/10.1016/0147-1767(91)90030-K

Zhang, J., \& Goodson, P. (2011). Predictors of international strudents psychosocial adjustment to life in United States: a systematic review. International Journal of Intercultural Relations, 35(2), 139-162. https://doi.org/10.1016/j.ijintrel.2010.11.011

Zhang, Q. (2004). Self-efficacy and intercultural adaptation of Chinese students at U.S. Universities. International \& Intercultural Communication Annual, 27, 103-120.

Zimmerman, S. (1995). Perceptions of intercultural communication competence and international student adaptation to an American campus. Communication Education, 44(4), 321-335.

https://doi.org/10.1080/03634529509379022

\section{Copyrights}

Copyright for this article is retained by the author(s), with first publication rights granted to the journal.

This is an open-access article distributed under the terms and conditions of the Creative Commons Attribution license (http://creativecommons.org/licenses/by/4.0/). 